\title{
Attitudes and beliefs of patients with chronic depression toward antidepressants and depression
}

\author{
This article was published in the following Dove Press journal: \\ Neuropsychiatric Disease and Treatment \\ 27 May 2015 \\ Number of times this article has been viewed
}

\author{
Sabrina Anne Jacob' \\ Ab Fatah Ab Rahman² \\ Mohamed Azmi Ahmad \\ Hassali $^{3}$ \\ 'School of Pharmacy, Monash \\ University Malaysia, Sunway, ${ }^{2}$ Faculty \\ of Health Sciences, Gong Badak \\ Campus, Universiti Sultan Zainal \\ Abidin (UniSZA), Kuala Terengganu, \\ ${ }^{3}$ School of Pharmaceutical Sciences, \\ University of Science Malaysia, \\ Minden, Malaysia
}

Background: Many patients have erroneous views with regard to depression and its management, and it was noted that these attitudes and beliefs significantly affected their adherence rates.

Objectives: The primary aim of this study was to determine the attitudes and beliefs of patients with depression toward depression and antidepressants. A secondary aim was to assess the influence of ethnicity on patients' attitudes and beliefs.

Patients and methods: The study involved patients with chronic depression being followed up at an outpatient clinic at a government-run hospital in Malaysia. Patients' attitudes and beliefs were assessed using the Antidepressant Compliance Questionnaire.

Results: A total of 104 patients of Malay, Chinese, and Indian ethnic groups met the selection criteria. Chinese patients had significantly negative attitudes and beliefs toward depression and antidepressants compared to Malays and Indians $\left(b=-8.96, t_{103}=-3.22 ; P<0.05\right)$. Component analysis revealed that $59 \%$ of patients believed that antidepressants can cause a person to have less control over their thoughts and feelings, while $67 \%$ believed that antidepressants could alter one's personality; $60 \%$ believed it was okay to take fewer tablets on days when they felt better, while $66 \%$ believed that antidepressants helped solve their emotional problems and helped them worry less.

Conclusion: Patients had an overall positive view as to the benefits of antidepressants, but the majority had incorrect views as to the acceptable dosing of antidepressants and had concerns about the safety of the medication. Assessing patients' attitudes and beliefs, as well as the impact of their respective cultures, can be used in tailoring psychoeducation sessions accordingly.

Keywords: Chinese, Malaysia, ethnicity, culture

\section{Introduction}

A large number of patients with depression have incorrect and negative views not only toward antidepressants but depression itself. ${ }^{1-6}$ The most common misperception among these patients is that depression is caused only by nonbiological or environmental factors, such as stress or family problems. ${ }^{7-9}$ Patients also believe that antidepressants are addictive, ${ }^{2,10,11}$ that they can alter the patient's personality, ${ }^{12,13}$ that fewer tablets can be taken on days when one feels better, and that extra tablets can be taken on days when they feel depressed. ${ }^{12}$

A significantly negative correlation has been found between patients' attitudes and beliefs toward depression and antidepressants and the percentage of days medication was missed. Therefore, subjects with negative attitudes missed their medications more frequently. ${ }^{11,12,14}$ In fact, research has shown that compared to side effects and demographics, patients' beliefs about a disease and its perceived controllability or consequences had a greater influence on patients' adherence rates. ${ }^{15,16}$ Indeed, it is also
Correspondence: Sabrina Anne Jacob School of Pharmacy, Monash University Malaysia, Jalan Lagoon Selatan, 47500

Bandar Sunway, Selangor, Malaysia

$\mathrm{Tel}+60355 \mathrm{l} 45885$

Email sabyj@hotmail.com 
one of the few alterable characteristics that can be targeted by clinicians in programs to increase adherence rates. ${ }^{12,15,17-19}$

Cultural differences in beliefs about diseases have resulted in different perceptions and ways in which people from different cultures seek treatment. ${ }^{8,20-22}$ Givens et al conducted a cross-sectional Internet survey where responses were rated using a 5-point Likert scale. The study involved 68,319 Caucasians, 3,596 African-Americans, 2,794 Asians/Pacific Islanders, and 3,203 Hispanics. Results revealed that African-Americans, Asians/Pacific Islanders, and Hispanics were less likely than Caucasians to attribute depression to biological factors or to believe that medicines were effective in treating depression, believing instead in nonpharmacological options, such as counseling and prayer. Other than that, a higher percentage believed antidepressants were addictive compared to Caucasians. ${ }^{23}$ In a cross-sectional study utilizing the Beliefs about Medication Questionnaire - general scale and Sensitive Soma Scale involving 83 Asians and 417 Europeans, Horne et al found that Asians had more negative views about medication compared to the Western population, and believed that prolonged use could lead to harm and addiction. ${ }^{21} \mathrm{~A}$ telephone survey by Cooper et al involving 659 Caucasians, 97 African-Americans, and 73 Hispanics found that Hispanics may be more concerned about the side effects of antidepressants than Caucasians. ${ }^{24}$

It is therefore important to determine the cultural aspects that influence the beliefs and attitudes of the patients, so that these erroneous beliefs can be addressed in an appropriate manner. ${ }^{3,12,15}$ Most studies however usually involve the Western population, which makes generalizability to the Asian population inaccurate; particularly those in the Southeast Asian region. There seems to be a false assumption that individuals on one end of the world would share similar health beliefs with individuals on the other end of the world simply because of a shared sex. ${ }^{25}$ As such, this study sought to elicit the attitudes and beliefs of patients toward antidepressants and depression, and to assess the influence of ethnicity on patients' attitudes and beliefs.

\section{Patients and methods}

This study was part of the Pharmacy-Managed Adherence Program study, a 6-month randomized prospective study designed to investigate the effect of the program on adherence levels. The study involved patients with chronic depression being followed up at the outpatient clinic of the psychiatric department of a government-run hospital in
Malaysia. ${ }^{26}$ Results reported here represent baseline data from the study.

All patients who were diagnosed with major depressive disorder according to the fourth edition of the Diagnostic and Statistical Manual of Mental Disorders, regardless of severity, and who had been on antidepressants for a minimum of 6 months were included in the study. Sample size was calculated for a type I error of 0.05 and a power of 0.80 . In order to detect an absolute difference of $25 \%$ in the proportion of patients judged to have adequate adherence and taking into account a predicted dropout rate of $30 \%$, the sample size needed was 160 patients. The following patients were excluded: patients with a comorbid psychiatric diagnosis, such as schizophrenia or bipolar disorder during the study period, patients $<18$ years of age, patients who were pregnant or breast-feeding, patients with current suicidal ideation or with a terminal illness, patients with dementia, cognitive disabilities, mental retardation, Alzheimer's, or Parkinson's, patients who did not understand/speak/read English or the national language (Bahasa Malaysia $[\mathrm{BM}]$ ), and patients who had no telephone.

Patients who agreed to participate and who signed informed consent forms were asked to fill in the Antidepressant Compliance Questionnaire (ADCQ), which was used to measure patients' attitudes and beliefs toward depression and antidepressants. Symptom severity was assessed using the Montgomery-Åsberg Depression Rating Scale (MADRS), ${ }^{27}$ which was administered by a trained psychiatrist. Demographic data as well as medical and psychiatric history were also obtained from each patient. Patients' files were also checked to see if they attended counseling sessions.

\section{Study instruments}

\section{Montgomery-Åsberg Depression Rating Scale}

The MADRS is a clinician-rated scale that consists of ten items, namely apparent sadness, reported sadness, inner tension, reduced sleep, reduced appetite, concentration difficulties, lassitude, inability to feel, pessimistic thoughts, and suicidal thoughts. For each item, the rating can range from 0 to 6 , where 0 equals no symptoms and 6 equals severe symptoms. The total score is then tabulated, and the following scoring system used to determine the patient's severity: 0-6 indicates recovery, 7-19 indicates mild depression, 20-34 indicates moderate depression, and 35 and above signifies severe depression. ${ }^{28}$ The time period covered by the scale is the clinical condition of the patient at the time of the interview. ${ }^{29}$ The scale is available in both the English 
and BM versions. The BM version was obtained from the MAPI Research Institute. ${ }^{30}$

\section{Antidepressant Compliance Questionnaire}

The ADCQ is a 33-item questionnaire that is divided into four components, namely: perceived doctor-patient relationship (component 1), preserved autonomy (component 2), positive beliefs on antidepressants (component 3 ), and partner agreement (component 4). Scoring is as follows: components 1 and 4: 1 - mostly disagree, 2 - rather disagree, 3 - rather agree, and 4 - mostly agree; component 2: 1 - mostly agree, 2 - rather agree, 3 - rather disagree, and 4 - mostly disagree. In component 3 , the items $8,23,26$, and 31 are scored as follows: 1 - mostly agree, 2 - rather agree, 3 - rather disagree, and 4-mostly disagree, while the other items are scored as follows: 1 - mostly disagree, 2 - rather disagree, 3 - rather agree, and 4 - mostly agree. Total score is 132 . The higher the score, the more positive the patient's beliefs and attitudes toward antidepressants and depression. ${ }^{31}$ The scale was translated to BM using Brislin's back-translation method, as proposed by the World Health Organization. ${ }^{32,33}$ Both the English and the BM scales were made available to the patients. Face and content validation of the BM version was conducted by the principal investigator and four psychiatric specialists from the hospital, while a testretest longitudinal design was used to analyze reliability.

\section{Statistical analysis}

Baseline demographic data are presented using descriptive statistics. Continuous variables are expressed by means and standard deviations, whereas categorical/nominal data are presented using frequency and percentage. For translation of the ADCQ, internal consistency was analyzed using Cronbach's $\alpha$. A measure of 0.70 and above was considered highly related. ${ }^{34}$ Test-retest reliability was explored at two time points, 2 weeks apart. Data were analyzed using Pearson's correlation. Results were considered to be significant at the $5 \%$ critical level $(P<0.05)$. MADRS and ADCQ were scored using the scoring algorithm described by the scale designers. Simple linear regression analyses were performed to determine independent influential factors for total ADCQ scores. The a priori level of significance was 0.05 , and all analyses were performed using SPSS 18.0 statistical software (SPSS Inc, Chicago, IL, USA).

\section{Ethical approval}

Ethical approval was sought and received from the Medical Research Ethics Committee (MREC) of Malaysia ([6]dlm. KKM/NIHSEC/O8/0804/P10-79).

\section{Results}

\section{Characteristics of study participants}

A total of 104 patients met the selection criteria and were administered the study instruments (Table 1). All patients, who were on once-daily dosing, were on only one antidepressant, except for two patients who were on two antidepressants. Of the 49 unemployed patients, $75.5 \%$ were women. Of these, 33 (67.3\%) were housewives.

Table I Demographics of study participants $(n=104)$

\begin{tabular}{|c|c|}
\hline Characteristics & Number (\%) of patients \\
\hline \multicolumn{2}{|l|}{ Sex } \\
\hline Male & $38(36.5)$ \\
\hline Female & $66(63.5)$ \\
\hline \multicolumn{2}{|l|}{ Race } \\
\hline Malay & $44(42.3)$ \\
\hline Chinese & $26(25.0)$ \\
\hline Indian & $34(32.7)$ \\
\hline Age, years (mean $\pm S D$ ) & $45.7 \pm 11.9$ \\
\hline Duration of disease, months (mean $\pm S D$ ) & $69.0 \pm 53.5$ \\
\hline \multicolumn{2}{|l|}{ Marital status } \\
\hline Single & $21(20.2)$ \\
\hline Married & $74(7 \mid .2)$ \\
\hline Divorced & $5(4.8)$ \\
\hline Widowed & $4(3.8)$ \\
\hline \multicolumn{2}{|l|}{ Education } \\
\hline Primary (year I-6) & $16(15.4)$ \\
\hline Secondary (year 7-13) & $64(6 I .5)$ \\
\hline Tertiary (diploma/university) & $24(23.1)$ \\
\hline Number of patients with employment & $55(52.9)$ \\
\hline \multicolumn{2}{|l|}{ MADRS symptom severity } \\
\hline Recovery & $38(36.5)$ \\
\hline Mild & $35(33.7)$ \\
\hline Moderate & $24(23.1)$ \\
\hline Severe & $7(6.7)$ \\
\hline \multicolumn{2}{|l|}{ Comorbid psychiatric disorders } \\
\hline Anxiety & $28(26.9)$ \\
\hline Obsessive-compulsive & $2(1.92)$ \\
\hline Panic & I (0.96) \\
\hline Phobia & I (0.96) \\
\hline PTSD & I $(0.96)$ \\
\hline \multicolumn{2}{|l|}{ Prescribed antidepressant } \\
\hline Fluvoxamine & $36(34.6)$ \\
\hline Sertraline & $24(23.1)$ \\
\hline Escitalopram & $18(17.3)$ \\
\hline Fluoxetine & $4(3.8)$ \\
\hline Venlafaxine & $9(8.7)$ \\
\hline Mirtazapine & $8(7.7)$ \\
\hline Duloxetine & $4(3.8)$ \\
\hline Dothiepin & $2(1.9)$ \\
\hline Amitriptyline & $\mathrm{I}(0)$ \\
\hline Attending psychological counseling & $17(16.3)$ \\
\hline
\end{tabular}

Abbreviations: SD, standard deviation; MADRS, Montgomery-Åsberg Depression Rating Scale; PTSD, posttraumatic stress disorder. 
Table 2 Internal consistency of ADCQ components

\begin{tabular}{lll}
\hline Component & Questions & Cronbach's $\alpha^{*}$ \\
\hline I & $2,5,7,12,14,15,16,19$, & 0.892 \\
& $20,21,22,25,27,28,29$ & \\
II & $1,3,6,9,13,24,30$ & 0.613 \\
III & $4,8,17,23,26,31,32,33$ & 0.641 \\
IV & $10,11,18$ & 0.909
\end{tabular}

Notes: *Cronbach's value $>0.70$ considered highly reliable.

Abbreviation: ADCQ, Antidepressant Compliance Questionnaire.

\section{Reliability analysis of ADCQ}

For the BM version of the ADCQ, Cronbach's $\alpha$ was 0.90 . Table 2 shows results when analyzed by components. Testretest analysis found a significant correlation for the BM version of the ADCQ $(r=0.75, P=0.013)$.
Patients' attitudes and beliefs

The mean total ADCQ score was 96.95 ( \pm 12.85$)$. Simple linear regression analyses revealed that total ADCQ scores were significantly predicted by Chinese ethnicity (Table 3). The four components of the ADCQ were analyzed separately (Table 4). Scores for the first two columns ("mostly disagree" and "rather disagree") were summed up to give a composite picture of what patients disagreed on, while the scores for the last two columns ("rather agree" and "mostly agree") were totaled to give a composite picture of what patients agreed on, as was done in a previous study. ${ }^{31}$

On component 1 (perceived doctor-patient relationship), more than $80 \%$ felt that their doctor listened properly to what they thought about antidepressants and stressed the importance

Table 3 Simple linear regression analysis for factors associated with ADCQ score in 104 patients with chronic depression

\begin{tabular}{|c|c|c|c|}
\hline \multirow[t]{2}{*}{ Model } & \multicolumn{3}{|l|}{ SLR } \\
\hline & $\boldsymbol{b}^{\ddagger}$ & $95 \% \mathrm{Cl}$ & $P$-value \\
\hline Age (years) & -0.19 & -0.40 to 0.02 & 0.07 \\
\hline Length of time in psychiatric care (months) & -0.02 & -0.07 to 0.03 & 0.38 \\
\hline \multicolumn{4}{|l|}{ Sex } \\
\hline Female & 1.0 & & \\
\hline Male & -0.88 & -6.09 to 4.34 & 0.74 \\
\hline MADRS score & -2.27 & -4.91 to 0.39 & 0.09 \\
\hline \multicolumn{4}{|l|}{ Education } \\
\hline Primary & 1.0 & & \\
\hline Secondary & 1.18 & -3.99 to 6.34 & 0.65 \\
\hline Tertiary & -0.23 & -5.74 to 6.19 & 0.94 \\
\hline \multicolumn{4}{|l|}{ Race } \\
\hline Malay & 1.0 & & \\
\hline Chinese ${ }^{\S}$ & -8.96 & -14.49 to -3.43 & $<0.01 *$ \\
\hline Indian & 2.13 & -3.22 to 7.47 & 0.43 \\
\hline \multicolumn{4}{|l|}{ Race } \\
\hline Chinese & 1.0 & & \\
\hline Indian & 2.13 & -3.22 to 7.47 & 0.43 \\
\hline Malay & 4.97 & -0.02 to 9.96 & 0.051 \\
\hline \multicolumn{4}{|l|}{ Race } \\
\hline Indian & 1.0 & & \\
\hline Chinese & -8.96 & -14.49 to -3.43 & $<0.01 *$ \\
\hline Malay & 4.97 & -0.02 to 9.96 & 0.051 \\
\hline \multicolumn{4}{|l|}{ Relationship status } \\
\hline Single & 1.0 & & \\
\hline Married & -0.77 & -6.31 to 4.47 & 0.78 \\
\hline Divorced & 2.36 & -9.37 to 14.10 & 0.69 \\
\hline Widowed & -2.03 & -15.09 to 11.03 & 0.76 \\
\hline \multicolumn{4}{|l|}{ Employment status } \\
\hline Yes & 1.0 & & \\
\hline No & -1.84 & -6.86 to 3.18 & 0.47 \\
\hline \multicolumn{4}{|l|}{ Attended counseling session } \\
\hline No & 1.0 & & \\
\hline Yes & 0.34 & -6.46 to 7.13 & 0.92 \\
\hline
\end{tabular}

Notes: ${ }^{\ddagger}$ Crude regression coefficient; $* P<0.05 ;{ }^{\S} r^{2}$ (coefficient of determination) $=0.09$

Abbreviations: ADCQ, Antidepressant Compliance Questionnaire; SLR, simple linear regression; Cl, confidence interval; MADRS, Montgomery-Åsberg Depression Rating Scale. 
Table 4 Component analysis of ADCQ of 104 patients with chronic depression

\begin{tabular}{|c|c|c|c|c|}
\hline Component $(n=104)$ & $\begin{array}{l}\text { Mostly } \\
\text { disagree (\%) }\end{array}$ & $\begin{array}{l}\text { Rather } \\
\text { disagree (\%) }\end{array}$ & $\begin{array}{l}\text { Rather } \\
\text { agree (\%) }\end{array}$ & $\begin{array}{l}\text { Mostly } \\
\text { agree (\%) }\end{array}$ \\
\hline \multicolumn{5}{|l|}{ Component I } \\
\hline My doctor listens properly to what I think about antidepressants & 5 & 13 & 36 & 47 \\
\hline $\begin{array}{l}\text { My doctor has made me feel confident that antidepressants } \\
\text { are the suitable treatment for my depression }\end{array}$ & 6 & 15 & 34 & 45 \\
\hline My doctor takes sufficient time to listen to my problems & 7 & 8 & 31 & 55 \\
\hline My doctor has explained the causes of my depression sufficiently & 13 & 17 & 29 & 40 \\
\hline $\begin{array}{l}\text { My doctor takes sufficient time to discuss my emotional } \\
\text { problems }\end{array}$ & 7 & 15 & 30 & 48 \\
\hline My doctor has explained depression sufficiently to me & 14 & 15 & 26 & 44 \\
\hline $\begin{array}{l}\text { My doctor shows sufficient consideration for my views } \\
\text { and feelings about his treatment with antidepressants }\end{array}$ & II & 9 & 42 & 38 \\
\hline $\begin{array}{l}\text { I receive sufficient psychological support and encouragement } \\
\text { from my doctor }\end{array}$ & 7 & 17 & 30 & 46 \\
\hline My doctor fully understands my condition & 7 & 15 & 29 & 49 \\
\hline \multicolumn{5}{|l|}{ the antidepressants regularly } \\
\hline My doctor is really interested in my problems & 6 & 17 & 32 & 45 \\
\hline $\begin{array}{l}\text { My doctor listens properly when I tell him what it is like } \\
\text { to be depressed }\end{array}$ & 4 & 12 & 42 & 42 \\
\hline $\begin{array}{l}\text { My doctor understands my feelings and thoughts on } \\
\text { depression perfectly }\end{array}$ & 10 & 15 & 37 & 38 \\
\hline $\begin{array}{l}\text { My doctor has explained properly about antidepressants, } \\
\text { their action, and side effects }\end{array}$ & 17 & 17 & 28 & 38 \\
\hline $\begin{array}{l}\text { My doctor listens properly to what I consider to be the } \\
\text { causes of my depression } \\
\text { Component } 2\end{array}$ & 9 & 11 & 39 & 41 \\
\hline $\begin{array}{l}\text { As long as you are taking antidepressants, you do not really } \\
\text { know if they are actually necessary }\end{array}$ & 21 & 19 & 31 & 29 \\
\hline $\begin{array}{l}\text { When you have taken antidepressants over a long period } \\
\text { of time, it is difficult to stop taking them }\end{array}$ & 16 & 25 & 29 & 30 \\
\hline $\begin{array}{l}\text { When you take antidepressants, you have less control over } \\
\text { your thoughts and feelings }\end{array}$ & 20 & 21 & 29 & 30 \\
\hline Antidepressants can alter your personality & 14 & 18 & 38 & 29 \\
\hline Your body can become addicted to antidepressants & 35 & 23 & 21 & 21 \\
\hline Your body can become immune to antidepressants & 28 & 17 & 35 & 20 \\
\hline Skipping a day now and again prevents your body from & 35 & 32 & 24 & 10 \\
\hline \multicolumn{5}{|l|}{ becoming immune to the antidepressants } \\
\hline \multicolumn{5}{|l|}{ Component 3} \\
\hline With antidepressants, the causes of my depression disappear & 4 & 14 & 34 & 48 \\
\hline $\begin{array}{l}\text { You may take fewer tablets than prescribed on days when } \\
\text { you feel better }\end{array}$ & 25 & 15 & 26 & 34 \\
\hline Antidepressants help me to worry less about my problems & 2 & 13 & 39 & 45 \\
\hline $\begin{array}{l}\text { If you forget to take the antidepressants on a certain day, } \\
\text { it is better to take an additional dose the following day }\end{array}$ & 64 & 24 & 6 & 6 \\
\hline $\begin{array}{l}\text { You may take more tablets than prescribed on days when } \\
\text { you feel more depressed }\end{array}$ & 51 & 17 & 18 & 13 \\
\hline $\begin{array}{l}\text { I think my depression is only due to factors associated with } \\
\text { my personality }\end{array}$ & 24 & 24 & 27 & 25 \\
\hline My emotional problems are solved by the antidepressants & II & 18 & 32 & 39 \\
\hline $\begin{array}{l}\text { Antidepressants make me stronger, so I will be able to deal } \\
\text { more efficiently with my problems }\end{array}$ & 6 & 24 & 32 & 38 \\
\hline Component 4 & & & & \\
\hline $\begin{array}{l}\text { My partner agrees that antidepressants are a suitable } \\
\text { treatment for my condition }\end{array}$ & 33 & 13 & 23 & 32 \\
\hline $\begin{array}{l}\text { Antidepressants correct the changes that occurred in my } \\
\text { brain due to stress or problems }\end{array}$ & 3 & 9 & 40 & 48 \\
\hline $\begin{array}{l}\text { My partner agrees that depression is the correct diagnosis } \\
\text { of my condition }\end{array}$ & 29 & 16 & 24 & 31 \\
\hline
\end{tabular}

Abbreviation: ADCQ, Antidepressant Compliance Questionnaire. 
of taking their antidepressants regularly, while 77\% agreed that their doctor provided sufficient psychological support and encouragement. On component 2 (preserved autonomy), more than $40 \%$ of patients believed that antidepressants were addictive, that the body could become immune to antidepressants, and that skipping a day now and again could prevent the body from becoming immune to them; 59\% believed it would be difficult to stop taking antidepressants when they have been taken over a long period of time, and a further $67 \%$ believed that antidepressants could alter one's personality.

On component 3 (positive beliefs on antidepressants), more than $30 \%$ of patients believed it was appropriate to take more tablets than prescribed on days when they felt more depressed, while $60 \%$ believed it was okay to take fewer tablets on days when they felt better. Sixty six percent believed that antidepressants helped solve their emotional problems, and helped them worry less. Meanwhile, $52 \%$ felt that depression was only due to factors associated with their personality. On component 4 (partner agreement), approximately $90 \%$ believed that antidepressants could correct the changes that occurred in their brain due to stress or problems.

\section{Discussion}

The mean total ADCQ score was 96.95, which was slightly less than that reported by Chakraborty et al who found a total mean score of 105.06. ${ }^{12}$ As there is no official scale for comparison proposed by the scale designers, we can surmise that the overall attitudes and beliefs of our patients toward depression and antidepressants were quite positive, given that the total score for all 33 items of the ADCQ would amount to 132. The majority of our respondents were female and young adults, and approximately $70 \%$ of those unemployed were housewives. These three characteristics could somewhat explain the more positive attitude based on results from previous studies. ${ }^{3,12,21}$

Simple linear regression analyses found that Chinese patients had significantly more negative attitudes and beliefs toward depression and antidepressants compared to Malay and Indian patients. In the Chinese culture, similar to that seen in South Koreans, mental illnesses are viewed as shameful not only to the individual but to the family as well. Jang et al noted that Asians of Chinese descent tend to follow Confucian ethics, which state that "self-concealment of emotional trouble is a virtue". ${ }^{3}$ Therefore, patients tend to tolerate the disease internally and suppress their emotions, instead of seeking treatment.

In our study, it was also observed that Malay patients had more positive attitudes and beliefs toward depression and antidepressants. Malaysia is a multiracial country made up of $60 \%$ Malays, more than $20 \%$ Chinese, and less than $10 \%$ Indians. By constitutional law, all Malays are Muslims.
In a study assessing suicide ideation in Malaysian patients, the more religious patients had significantly lower suicide ideation scores, and this was most pronounced in Muslims. ${ }^{35}$ Therefore, we can postulate that greater religiosity in Malay patients compels them to seek treatment, as suicide is prohibited in Islam. ${ }^{36}$ Studies have also shown that Chinese and Indian patients prefer traditional therapy, such as ayurveda, or "sin sehs", compared to Western medication; which could explain their more negative attitudes and beliefs toward antidepressants as compared to Malay patients. ${ }^{3,7,37}$

In keeping with results found by Demyttenaere et al, ${ }^{31}$ Chakraborty et $\mathrm{al}^{12}$ and other studies, ${ }^{38,39}$ no significant relationship was found between symptom severity and ADCQ scores. There was no significant correlation between ADCQ scores and sex, age, and attending counseling sessions either.

\section{Component analysis}

On component 1 , the majority of patients gave positive feedback as to the care received from their doctors. It must however be taken into account that Asians tend to have very high respect for doctors and view them almost as gods. ${ }^{12}$ In answering this section, a few patients expressed concern, as they were worried whether the doctors could view their answers and were concerned about the repercussions; therefore, results could have been compromised.

With regard to component 2 , roughly $60 \%$ of respondents believed that as long as they were taking antidepressants, they were not sure if they were actually necessary, and that the medication made them have less control over their thoughts and feelings. In previous studies, patients expressed negative views about antidepressants and felt they reduced their alertness. ${ }^{8,13,31}$ A large number of patients in our study also believed that antidepressants could alter one's personality, and that one could become immune to the drugs. Indeed, studies have revealed that patients were worried that taking antidepressants on a daily basis could be harmful to the body. ${ }^{6,40}$

Approximately $60 \%$ of patients felt that it was difficult to stop taking antidepressants once one had started taking them, and this is true especially with regard to certain antidepressants, such as mirtazapine and venlafaxine, which cannot be stopped abruptly, and instead have to be tapered off over several days to weeks. Many patients in our study also believed that antidepressants could cause addiction, echoing several studies or reviews where patients either expressed a concern over the potential for addiction with antidepressants or simply stopped their medication completely due to fear of addiction. . $^{2,8,13,18,20,41}$ This is because most people tend to confuse antidepressants with tranquilizers, which have the potential for addiction, since most antidepressants also cause drowsiness. ${ }^{42}$ 
In component 3 , the majority of our patients had positive beliefs regarding antidepressants, with more than $80 \%$ believing they helped them worry less about their problems and $70 \%$ believing they solved their problems. This is contrary to studies conducted in Western populations, as well as studies involving Asians living in Western countries, where the majority of patients had negative views toward antidepressants. ${ }^{18,21,23,31}$ Western cultures are more individualistic, and place importance on asserting individual independence and autonomy. Eastern cultures, on the other hand, stress that responsibility to the community is greater than duty to oneself. This could somewhat explain why Easterners have more favorable views, as they feel antidepressants will help them maintain the status quo in the community. ${ }^{25}$ In a paper by Horne et al, Asians reported less experience with prescribed medication compared to the Western population. ${ }^{21}$ This is not surprising, given that many Asians tend to resort first to traditional medicine. ${ }^{3,7,37}$ However, having more experience with medication could also mean that the Western population are more aware of the side effects associated with these medications, and this perhaps has elicited more negative views toward antidepressants. Our results also show that we cannot assume similarity with Asians living in Western countries, as there is the issue of cross-culture influence from their adoptive country. Therefore results obtained from those studies cannot necessarily be applied to our population. ${ }^{21,23}$

A substantial number of patients in this study however seem to have erroneous views with regard to the dosing of antidepressants. More than 30\% believed extra doses could be taken on days when they felt low, and $60 \%$ believed it was acceptable to take fewer doses on days when they felt better. Patients tend to go on "drug holidays" or alter their doses when they feel better, and a study found a significant correlation between patients who stopped their medication when they felt better with perceived stigma toward depression. This could explain our findings with regard to the cultural stigma, whereby patients want to stop the medication as soon as possible. ${ }^{43}$

Finally, more than $50 \%$ of respondents believed that depression was caused by their own personality. This is similar to other studies, where the majority believed that depression was mainly a psychological problem and not a medical problem. ${ }^{4,13,20,44}$ This points to the nature of patients who prefer to support only a nonbiological cause of depression, which then causes them to reject biological interventions, ie, antidepressants in moderateto-severe cases, as they feel they can heal themselves by simply changing their behavior or personality. ${ }^{8}$

\section{Limitations}

We were unable to reach the target sample size due to the strict inclusion and exclusion criteria with regard to language requirements. As mentioned earlier, patients were rather hesitant to answer the questionnaires for fear that the doctors would see their responses. This too could have affected the final results obtained. Given that this study only involved one center where the majority of patients came from low to middle socioeconomic backgrounds, this might somewhat limit the generalizability of the results.

\section{Conclusion}

The majority of patients gave very positive feedback with regard to the care received from the physicians, and a substantial amount also believed in the effectiveness of antidepressants. However, most patients had erroneous views with regard to the perceived harmful effects of antidepressants. Patients' beliefs and attitudes influence their adherence, outcome, and preference for treatment. By understanding patients' beliefs about their treatment, as well as the impact of their respective cultures, clinicians can alter treatment accordingly, either through the dissemination of information or through improved patient-prescriber relationships. More detailed research should also be done to assess the influence of ethnicity on patients' attitudes and beliefs, so as to ensure the generalizability of research outcomes.

\section{Acknowledgments}

We wish to thank the staff of the Psychiatric Department of Hospital Tengku Ampuan Rahimah, Klang for their help in conducting the research. This study was supported by a grant from the Research and Creativity Management Office (RCMO) of Universiti Sains Malaysia (304/ PFARMASI/6311025).

\section{Author contributions}

All authors contributed toward data analysis and drafting and revising the paper, and agree to be accountable for all aspects of the work.

\section{Disclosure}

The authors report no conflicts of interest in this work.

\section{References}

1. Brown C, Dunbar-Jacob J, Palenchar DR, et al. Primary care patients' personal illness models for depression: a preliminary investigation. Fam Pract. 2001;18(3):314-320.

2. Conner KO, Lee B, Mayers V, et al. Attitudes and beliefs about mental health among African American older adults suffering from depression. J Aging Stud. 2010;24(4):266-277. 
3. Jang Y, Chiriboga DA, Okazaki S. Attitudes toward mental health services: age-group differences in Korean American adults. Aging Ment Health. 2009;13(1):127-134.

4. Jorm AF, Christensen H, Griffiths KM. Belief in the harmfulness of antidepressants: results from a national survey of the Australian public. $J$ Affect Disord. 2005;88(1):47-53.

5. Kermode M, Bowen K, Arole S, Joag K, Jorm AF. Community beliefs about treatments and outcomes of mental disorders: a mental health literacy survey in a rural area of Maharashtra, India. Public Health. 2009; 123(7):476-483.

6. Waite R, Killian P. Health beliefs about depression among African American women. Perspect Psychiatr Care. 2008;44(3):185-195.

7. Khan TM, Sulaiman SA, Hassali MA. Mental health literacy towards depression among non-medical students at a Malaysian university. Ment Health Fam Med. 2010;7(1):27-35.

8. Prins MA, Verhaak PF, Bensing JM, van der Meer K. Health beliefs and perceived need for mental health care of anxiety and depression - the patients' perspective explored. Clin Psychol Rev. 2008; 28(6):1038-1058.

9. Swami V, Loo PW, Furnham A. Public knowledge and beliefs about depression among urban and rural Malays in Malaysia. Int $J$ Soc Psychiatry. 2010;56(5):480-496.

10. Garfield S, Francis SA, Smith FJ. Building concordant relationships with patients starting antidepressant medication. Patient Educ Couns. 2004;55(2):241-246.

11. Holma IA, Holma KM, Melartin TK, Isometsä ET. Treatment attitudes and adherence of psychiatric patients with major depressive disorder: a five-year prospective study. J Affect Disord. 2010;127(1-3): 102-112.

12. Chakraborty K, Avasthi A, Kumar S, Grover S. Attitudes and beliefs of patients of first episode depression towards antidepressants and their adherence to treatment. Soc Psychiatry Psychiatr Epidemiol. 2009;44(6): $482-488$.

13. Kessing LV, Hansen HV, Demyttenaere K, Bech P. Depressive and bipolar disorders: patients' attitudes and beliefs towards depression and antidepressants. Psychol Med. 2005;35(8):1205-1213.

14. Jin J, Sklar GE, Oh VM, Shu CL. Factors affecting therapeutic compliance: a review from the patient's perspective. Ther Clin Risk Manag. 2008;4(1):269-286.

15. Horne R, Weinman J. Patients' beliefs about prescribed medicines and their role in adherence to treatment in chronic physical illness. J Psychosom Res. 1999;47(6):555-567.

16. Scott J. Using health belief models to understand the efficacyeffectiveness gap for mood stabilizer treatments. Neuropsychobiology. 2002;46 Suppl 1:13-15.

17. Edlin M. Lack of education affects behavioral health medication compliance. 2008. Available from: http://managedhealthcareexecutive. modernmedicine.com/managed-healthcare-executive/content/lackeducation-affects-behavioral-health-medication-compliance?page=full. Accessed May 4, 2015.

18. Hoencamp E, Stevens A, Haffmans J. Patients' attitudes toward antidepressants. Psychiatr Serv. 2002;53(9):1180-1181.

19. Vermeire E, Hearnshaw H, Van Royen P, Denekens J. Patient adherence to treatment: three decades of research. A comprehensive review. J Clin Pharm Ther. 2001;26(5):331-342.

20. Carter P, Al-Saffar N, Deshmukh A, Eid S. Health beliefs and drug compliance of depressed patients in Kuwait. J Soc Adm Pharm. 2003;20(4): $142-150$.

21. Horne R, Graupner L, Frost S, Weinman J, Wright SM, Hankins M. Medicine in a multi-cultural society: the effect of cultural background on beliefs about medications. Soc Sci Med. 2004;59(6):1307-1313.

22. Leventhal H, Cameron L. Behavioral theories and the problem of compliance. Patient Educ Couns. 1987;10(2):117-138.
23. Givens JL, Houston TK, Van Voorhees BW, Ford DE, Cooper LA. Ethnicity and preferences for depression treatment. Gen Hosp Psychiatry. 2007;29(3):182-191.

24. Cooper LA, Gonzales JJ, Gallo JJ, et al. The acceptability of treatment for depression among African-American, Hispanic, and white primary care patients. Med Care. 2003;41(4):479-489.

25. Hussain FA, Cochrane R. Depression in South Asian women: Asian women's beliefs on causes and cures. Ment Health Relig Cult. 2002; 5(3):285-311

26. Jacob SA, Ab Rahman AF, Hassali MA. Health-related quality of life of patients with chronic depression in Malaysia. Malays J Psychiatry. 2014;23(1):57-67.

27. Montgomery S, Asberg M. A new depression scale designed to be sensitive to change. Br J Psychiatry. 1979;134(4):382-389.

28. Snaith R, Harrop F, Newby D, Teale C. Grade scores of the Montgomery-Asberg Depression and the Clinical Anxiety scales. $\mathrm{Br}$ J Psychiatry. 1986;148(5):599-601.

29. Karlsson H, Lehtinen V, Joukamaa M. Psychiatric morbidity among frequent attender patients in primary care. Gen Hosp Psychiatry. 1995; 17(1):19-25.

30. MAPI Research Trust. Questionnaires. Available from: http://www. proqolid.org/. Accessed June 2, 2009.

31. Demyttenaere K, Bruffaerts R, Albert A, et al. Development of an antidepressant compliance questionnaire. Acta Psychiatr Scand. 2004; 110(3):201-207.

32. Cha ES, Kim KH, Erlen JA. Translation of scales in cross-cultural research: issues and techniques. $J$ Adv Nurs. 2007;58(4):386-395.

33. World Health Organization. Management of substance abuse: process of translation and adaptation of instruments. 2015. Available from: http://www.who.int/substance_abuse/research_tools/translation/en/ index.html. Accessed November 16, 2009.

34. Pan AW, Chen YL, Chung LI, Wang JD, Chen TJ, Hsiung PC. A longitudinal study of the predictors of quality of life in patients with major depressive disorder utilizing a linear mixed effect model. Psychiatry Res. 2012;198(3):412-419.

35. Zainal NZ, Sulaiman AH. Religiosity and suicide ideation in clinically depressed patients. Malays J Psychiatry. 2007;16(1):12-15.

36. Sabry WM, Vohra A. Role of Islam in the management of psychiatric disorders. Indian J Psychiatry. 2013;55 Supp1 2:S205-S214.

37. Wu P, Fuller C, Liu X, et al. Use of complementary and alternative medicine among women with depression: results of a national survey. Psychiatr Serv. 2007;58(3):349-356.

38. Kanae S, Hiroto I, Asuka K, Miyuki T, Teruhiko H. The effect of an educational leaflet on depressive patients' attitudes toward treatment. Psychiatry Res. 2010;177(1):184-187.

39. Vergouwen AC, Bakker A, Burger H, Verheij TJ, Koerselman F. A cluster randomized trial comparing two interventions to improve treatment of major depression in primary care. Psychol Med. 2005;35(1): 25-33.

40. Bultman DC, Svarstad BL. Effects of physician communication style on client medication beliefs and adherence with antidepressant treatment. Patient Educ Couns. 2000;40(2):173-185.

41. Priest RG, Vize C, Roberts A, Roberts M, Tylee A. Lay people's attitudes to treatment of depression: results of opinion poll for Defeat Depression Campaign just before its launch. BMJ. 1996;313(7061):858-859.

42. Angermeyer MC, Matschinger H. Public attitude towards psychiatric treatment. Acta Psychiatr Scand. 1996;94(5):326-336.

43. Gabriel A, Violato C. Knowledge of and attitudes towards depression and adherence to treatment: the Antidepressant Adherence Scale (AAS). $J$ Affect Disord. 2010;126(3):388-394.

44. Hansson M, Chotai J, Bodlund O. Patients' beliefs about the cause of their depression. $J$ Affect Disord. 2010;124(1-2):54-59. 
Neuropsychiatric Disease and Treatment

Dovepress

\section{Publish your work in this journal}

Neuropsychiatric Disease and Treatment is an international, peerreviewed journal of clinical therapeutics and pharmacology focusing on concise rapid reporting of clinical or pre-clinical studies on a range of neuropsychiatric and neurological disorders. This journal is indexed on PubMed Central, the 'PsycINFO' database and CAS,

and is the official journal of The International Neuropsychiatric Association (INA). The manuscript management system is completely online and includes a very quick and fair peer-review system, which is all easy to use. Visit http://www.dovepress.com/testimonials.php to read real quotes from published authors.

\footnotetext{
Submit your manuscript here: http://www.dovepress.com/neuropsychiatric-disease-and-treatment-journal
} 